\title{
Nem ve Frekansa Bağlı Olarak Kayısı ve Erik Yapraklarının Dielektrik Özelliklerinin Dalga Kılavuzu İletim Hattı Yöntemiyle Belirlenmesi
}

\author{
Determination of Dielectric Properties of Apricot and Plum Leaves by Waveguide \\ Transmission Line Method depending on Moisture Content and Frequency
}

\author{
Habib DOĞAN* \\ Çevre ve Şehircilik il Müdürlüğ̈̈, 32300, Isparta
}

• Geliş tarihi / Received: 09.08.2019 • Düzeltilerek geliş tarihi / Received in revised form: 24.10.2019 • Kabul tarihi / Accepted: 13.11 .2019

\begin{abstract}
Öz
Gelişen teknolojiyle birlikte tarımsal ürünlerdeki uygulamalar gün geçtikçe yaygınlaşmaktadır. Bu uygulamalarda temel belirleyici parametre, bitkisel malzemenin dielektrik özelliğinin belirlenmesidir. Çünkü malzemeye nüfuz eden elektromanyetik (EM) dalganın malzemeyle nasıl etkileşeceği dielektrik özelliklerine de bağlıdır. Üretimde verim ve kalitenin artmasını sağlayan uzaktan algılama (UA) ile kurutma ve ısıtma teknolojilerinin etkin çalışabilmesi, malzemenin dielektrik karakteristiğiyle ilişkilidir. Bu çalışmada, Türkiye'de çok yaygın olarak üretimi yapılan kayısı ve erik ağaçlarının yapraklarının dielektrik parametreleri iletim hattı yöntemi kullanılarak ölçülmüştür. Ölçümler 3,30-4,90 $\mathrm{GHz}$ arasında (WR229 dalga kılavuzu için) yapılmış ve nem oranı ve frekansa bağlı kayısı ve erik yapraklarının dielektrik karakteristikleri incelenmiştir. Kayısı yapraklarının dielektrik ölçüm verilerini kullanarak frekans ve nem oranına bağl1, eğri uydurma yöntemiyle yeni bir model önerilmiştir. Bu model, kayısı türüyle aynı aileden olan erik yaprağının dielektrik ölçüm sonuçlarıyla karşılaştırılarak önerilen modelin doğruluğu test edilmiştir. Modelin performansını görmek için determinasyon katsayısı R2 ve Hataların Ortalama Kare Kökü (RMSE) değerleri sırasıyla 0.996 ve 0.653 olarak elde edilmiştir.
\end{abstract}

Anahtar kelimeler: Dielektrik Ölçümü, Erik Yaprağı, Kayısı Yaprağı, Nem Oranı, NRW Algoritması

\begin{abstract}
With developing technology, applications in agricultural products are becoming more common. The main dominant parameter in these applications is the determination of the dielectric property of the plant material. Because how the electromagnetic (EM) wave penetrating the material interacts with the material depends on its dielectric properties. The ability of remote sensing $(R S)$ and drying and heating technologies to increase efficiency and quality in production is related to the dielectric characteristics of the material. In this study, the dielectric parameters of leaves of apricot and plum trees made widely produced in Turkey are measured by using the transmission line technique. Measurements are conducted between 3.30-4.90 GHz (for WR229 waveguide) and dielectric characteristics of apricot and plum leaves depending on moisture content and frequency are investigated. A new model is proposed by a curve fitting method based on frequency and moisture content using dielectric measurement data of apricot leaves. This model is compared with the dielectric measurement results of the plum leaves of the same family as the apricot type and the accuracy of the proposed model is tested. To make sure the performance of the model well enough, the coefficient of determination R2 and Mean Square Root of Error (RMSE) values are obtained as 0.996 and 0.653, respectively.
\end{abstract}

Keywords: Dielectric Measurement, Plum Leaf, Apricot Leaf, Moisture Content, NRW Algorithm

*Habib DOĞAN; habib.dogan@csb.gov.tr, Tel: (0246) 22413 00, orcid.org/0000-0001-8685-9569 


\section{Giriş}

Tarımsal uygulamalarda uzaktan izleme/kontrol ve uzaktan algilama (UA) sistemleri yaygın olarak kullanılır. $\mathrm{Bu}$ sistemler, geleneksel yöntemlere göre üretimde kalite ve verim artışına yol açar. $\mathrm{Bu}$ yeni teknolojilerin, biyolojik bitki örtülerinde doğru bir biçimde kullanılabilmeleri için bitki örtüsünü oluşturan bitkisel malzemelerin (yaprak, dal, meyve, vb.) dielektrik parametrelerinin belirlenmesine ihtiyaç bulunmaktadır. Çünkü bitki örtüsüne uygulanacak elektromanyetik (EM) dalgaların bitki örtüsündeki malzemelerle nasıl etkileşeceği tamamen ortamın dielektrik parametreleri tarafindan belirlenir (Ulaby ve Jedlika, 1984). Bitki kümesine gelen elektromanyetik (EM) dalgalar, bitkilerin yaprak, gövde, dal ve meyve yüzeylerine nüfuz eder ve yüzeyde yansıma, kırılma, soğurulma ve saçılma gibi EM davranışları gerçekleşir.

Bazı bitkilere yönelik teknolojik uygulamalar, mikrodalga 1sitma/kurutma, soğurucu malzeme tasarımı ve UA uygulamaları olarak kategorize edilebilir. Mikrodalga 1sitma/kurutma işlemleri, bitkilerin dielektrik parametreleri dikkate alınarak yapılır ve geleneksel yöntemlere göre zaman ve enerji açısından bazı avantajlara sahiptir (Navarrete vd., 2011; Kamuriddin vd., 2017). Bu yöntemlerle bitkisel ürünler, hasat sonrası sağlklı ve uzun süreli depolanabilirler. Ayrıca bu ürünlerin, zararlı haşerattan korunmaları da sağlanır (Trabelsi, 2016; Shrestha, 2011). Günümüzde, soğurucu malzeme olarak kullanılan polimer tabanlı materyallerin zamanla soğurma özelliğini kaybetmesi ve sağlık/çevre açısından riskler barındırmas1, organik bitkisel malzemelerden soğurucu malzemesi üretme çalışmalarını hızlandırmıştır. $\mathrm{Bu}$ amaçla, lifli bitkilerin soğurma özellikleri araştırılmıştır (Colak, 2019; Kaur, 2015). Muz, yaprak ve kabukları, içerdiği karbon miktarına bağlı olarak soğurucu malzeme olarak kullanılabilmektedir ve muz yapraklarına belli oranda katkı malzemesi eklenmesiyle soğurma özelliğinin artırılabileceği tespit edilmiştir (Jayamani vd., 2016).

Belli bölgelerde yoğunlaşan bitki türlerinin yayılım etkileri değişik çalışmalarla ortaya konulmuştur (Ramanov ve Ulanov, 2018). Bitki örtüsünün dielektrik parametreleri belirlenerek, kırılma, yansıma ve saçılma gibi EM davranışları öngörülebilir (Ulaby ve El Rayes, 1987; Chuah, 1997). UA uygulamaları, tarım ve özellikle askeri alanlarda yaygin olarak kullanılır. $\mathrm{Bu}$ uygulamadaki mikrodalga teknolojisi, diğer teknolojilere göre çeşitli avantajlar içerir. Bunlar: mikrodalgaların, gece ve bulutlu havalarda çalışmaya elverişli olması, bitki örtüsündeki suya karşı duyarlı olması ve bitki ve toprağa belli bir seviyede nüfuz edebilme kabiliyetinin olmasıdır (Kocakuşak vd., 2016).

Bitkisel malzemelerle ilgili tüm çalışmalarda temel motivasyon, bu malzemelerin dielektrik özelliklerinin belirlenmesidir. Yapılan çalışmalarda bu malzemelerinin dielektrik geçirgenliğinin, büyük oranda bitkinin içerdiği su miktarına bağlı olduğu görülmüştür (Trabelsi, 2016; Kraszewski ve Nelson, 2004). Ayrica ortaya konulan modellerde bitkisel malzemelerin (yaprak, dal, meyve, vb.) ortalama dielektrik geçirgenliğinde yaprakların daha baskın olduğu gözlenmiştir (Chuah, 1997)

Kayıplı ortamlarda kompleks dielektrik sabitinin reel kısmı $\left(\varepsilon^{\prime}\right)$, EM enerjinin malzeme içerisinde ne kadar depo edildiğini belirlerken, sanal kısmı ise EM yayılım hızını, zayıflamayı ve iletim parametrelerini belirler. Genel olarak, homojen, yön bağımsız ve kayıplı bir ortam için kompleks dielektrik sabiti Denklem 1'de verilmiştir.

$\varepsilon^{*}=\varepsilon^{\prime}-j \varepsilon^{\prime \prime}$

Burada, malzemenin kayıp tanjantı $\varepsilon^{\prime \prime} / \varepsilon^{\prime}$ olduğu için Denklem 2'deki gibi ifade edilir. Malzeme içerisindeki güç kaybının, frekansa ve malzemenin dielektrik sabitine bağlı olduğu bu denklemde görülmektedir (Faktorová ve Isteníková, 2011).

$\tan \delta=\frac{\varepsilon^{\prime \prime}}{\varepsilon^{\prime}}=\frac{\sigma}{\omega \varepsilon_{r} \varepsilon_{0}}$

Bitkilerde dielektrik parametre ölçümleri 1910'lu yıllara dayanmasına rağmen son yıllarda bu çalışmalara olan ilgi gittikçe artmıştır (Nelson, 2006). Bu konu ile ilgili ilk çalışmalar ampirik düzeyde olup, daha sonraki çalışmalarda ise dielektrik ölçüm sonuçlarının verileri elde edilmeye başlanmıştır (Nelson, 1991).

Bazı bitkilerin dilektrik parametrelerinin belirlenmesinde çeşitli teknikler kullanılmaktadır. $100 \mathrm{MHz}$ 'in alt frekans bölgesinde paralel plaka ve toplu elemanlar yöntemleri kullanılır iken, daha üst frekans bölgelerinde ise iletim hatt1, koaksiyel prob, boşluk rezonatörü, dalga kılavuzu iletim hattı ve serbest uzay ölçüm teknikleri kullanılır (Venkatesh ve Raghavan, 2005; Khaled vd., 2015; Krraoui, 2016). Bu çalışmalarda, genel olarak bitkilerin içerdiği su miktarına bağlı olarak 
belli frekans aralıklarındaki dielektrik parametreler ölçülmüştür. Bitki yaprakları koparılmadan yapılan dielektrik ölçüm çalışmaları (van Emmerik, 2015) koparıldıktan sonra farklı NO değerleri için yapılan çalışmalar ve tamamen toz haline getirilerek gerçekleştirilen ölçüm çalışmaları mevcuttur (Afzal ve Mousavi, 2008; Baharudin vd., 2015). Genelde tahıl ürünleri olmak üzere özellikle misır bitkisi üzerinde çok fazla çalışma yapılmıştır (Kraszewski ve Nelson, 2004; Afzal ve Mousavi, 2008) ve bu sayede meyvelerin olgunlaşması ve kalitelerinin belirlenmesinin gerçekleştirilebilirliği incelenmiştir (Nelson, 1991).

Erik ve kayıs1, aynı familya (Rosacea), aynı takım (Rosales) ve ayn cinse (Prunus) ait iki meyve türüdür. Kayısı üretiminde Türkiye yıllık yaklaşık 800.000 ton üretimle dünyada birinci sirada iken erik üretiminde 250 bin tona yaklaşan yıllık üretimi ile yedinci sıradadır. Türkiye'de kayısı üretimi daha çok Malatya ve Erzincan bölgeleriyle özdeşleşmiş olsa da hemen hemen tüm bölgelerde kayıs1 üretimine rastlanılmaktadır. Türkiye, kayıs1 üretiminde dünyada ilk sirada yer almasina rağmen, ihracat miktarlarına bakıldığında diğer ülkelerin gerisinde kaldığı görülmektedir. $\mathrm{Bu}$ durum, tarımsal uygulamalardaki teknolojik uygulamaların eksikliğine bağlı olarak verim ve kalitede yaşanılan sorunlardan kaynaklanmaktadır. Tarımsal ürünlerin gerek yönetimindeki otomasyon gerekse de UA uygulamalarıyla verim artışının gerçekleşeceği düşünülmektedir. $\mathrm{Bu}$ tespit bu çalışmadaki temel motivasyonumuz olmuştur.

$\mathrm{Bu}$ çalışmada, sabit sıcaklıkta nem oranı (NO) ve frekansa bağlı olmak üzere birbiriyle aynı aile ve takımdan olan kayısı ve erik yapraklarının dielektrik karakteristikleri ölçüm sonuçlarıyla elde edilmiştir. Kayısı yapraklarının dielektrik ölçüm verilerini kullanarak eğri uydurma yöntemiyle yeni bir model önerilmiştir. $\mathrm{Bu}$ modelin doğruluğu kayısı türüyle aynı cinsten olan erik yaprağıyla ilgili dielektrik ölçümlerle test edilmiştir. Ölçümlerde dalga kılavuzu iletim hattı tekniği kullanılmıştır. Ölçümler WR229 dalga k1lavuzuyla $3.30-4.90 \mathrm{GHz}$ frekans bandında yapılmıştır. $\mathrm{Bu}$ çalışmadaki ölçüm sonuçlarının 3,30-4,90 GHz frekans aralığında verilmesinin iki nedeni vardır. Öncelikle, literatürde misır ve pirinç vb. gibi bazı bitkilerin boylarını izlemek ve nem oranına bağlı bitkinin dielektrik sabitini kullanarak bitkinin su ihtiyacını tespit etmek için S-bandında çalışan Sentetik Açıklıklı Radar (SAR) tekniğinin kullanılması (Ballester vd., 2005), ikinci olarak, ölçümlerde kullanılan
WR229 dalga k1lavuzunun 3,3-4,9GHz bandinda çalışması ve bu frekans bandının ağırlıklı olarak S-bandında bulunmasıdır. Çalışmanın 2. bölümünde kullanılan dielektrik ölçüm yöntemi verilmiştir. 3. bölüm, elde edilen ölçüm sonuçları ve önerilen modelden oluşur ve 4 . bölümde sonuçlar değerlendirilmiştir.

\section{2. Ölçüm ve Test Hazırlığı}

Ölçüm yöntemi olarak bu çalışmada Dalga Kılavuzu İletim Hattı yöntemi kullanılmıştır. Bu yöntemde hangi frekans aralığında ölçüm yapılacaksa ilgili dalga kılavuzu seçilmiştir. Dalga kılavuzu, Vektör Network Analizör'e (VNA) RF koaksiyel kabloyla bağlanmıştır. Giriş ve çıkış portlarına bağlı olan iki dalga kılavuzu ve uyumlu bir flanş kullanılmıştır. Ölçülen numuneler (kayısı ve erik yaprakları), flanş ile WR229 dalga kılavuzu arasına yerleştirilerek ölçüme hazır hale getirilirler. Dielektrik ölçümler 3,30-4,90 GHz (WR229 dikdörtgen dalga kılavuzu) aralığında yapılmıştır. VNA olarak Anritsu MS4624B modeli $(10 \mathrm{MHz}-9 \mathrm{GHz})$ kullanılmıştır. Ölçümlerde kullanılan numunelerin kurutulma aşamasında kıvrılma ve kırılmaları engellemek için 2,8 mm kalınlığa sahip şeffaf plastik cam (plexiglass) tercih edilmiştir. Burada kullanılan plastik camların dielektrik ölçümlerde küçük bir etkisi bulunur. $\mathrm{Bu}$ etki, dielektrik ölçümlerin hesabında dikkate alınmalıdır. Yaprakların kurutulmasını sağlamak için plastik cam üzerinde CNC yöntemiyle 7×4'lük 1 mm'lik eşit mesafede delikler açılmıştır. Numuneler ölçümden önce 36 saat boyunca saf suda bekletilerek suya doymuş hali ile ölçüme hazır hale getirilmiştir. Numunelerin suda bekletildiği bu süre içerisinde ağılıkları her 12 saatte bir ölçülmüş ve 36 . saat sonunda ağırlığında ciddi bir değişim gözlenmemiştir. Ölçümler suda bekletilen toplam sürenin hesaba katılmadığ durumda yaklaşık 2 gün sürmüştür.

Ölçüme başlamadan önce suya doymuş yapraklar WR229 dalga k1lavuzu boyutlarına uygun olarak maket biçağıyla kesilmiştir. Dielektrik ölçümlerinde numunelerin $S_{11}$ ve $S_{21}$ parametreleri ölçülmüş ve ağıllıkları mgr hassasiyetine sahip hassas bir terazi ile ölçülmüştür. Suya doymuş yapraklar, mikrodalga firında adım adım kurutulmuştur. Her bir adımda $S_{11}$ ve $S_{2 l}$ ölçümleri tekrar alınmıştır. Numunelerin kurutma ve ölçüm adımları, yapraklar tamamen kuruyana kadar devam etmiştir. Son kurutma aşamasından sonra, firın içerisindeki sıcaklık $70^{\circ}$ iken numune bu ortamda 12 saat bekletilerek numunelerin 
tamamen kurutulması sağlanmıştır. Ölçümler $24^{\circ} \mathrm{C}$ oda sıcaklığında yapılmıştır.

Şekil 1'de ölçüm düzeneği verilmiştir. Şekil 1a'da dalga kılavuzlarıyla beraber ölçüme hazır olan
VNA görülmektedir. Şekil $1 \mathrm{~b}$ ve Şekil 1c, sırasıyla içi boş ve içi plastik camla dolu flanş bulunmaktadır. Şekil 1d ve Şekil 1e'de ise sırasıyla erik ve kayısı yaprakları verilmiştir.

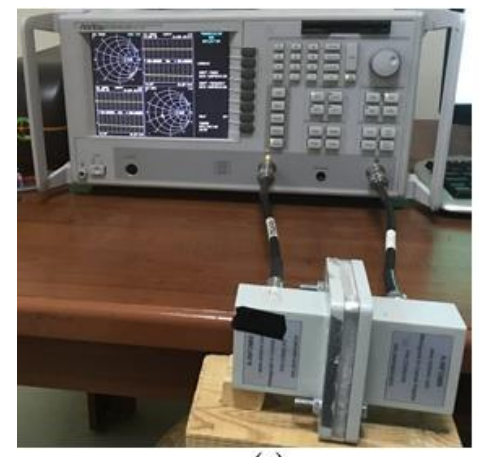

(a)
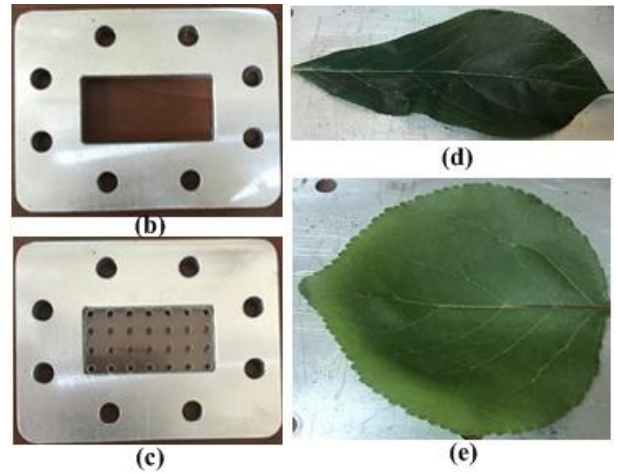

(e)

Şekil 1. Ölçüm düzeneği

Giriş bölümünde belirtildiği gibi numunelerin kurutulma süreci adım adım gerçekleştirilmiştir. Tablo 1'de erik ve kayıs1 yapraklarının WR229 için yapılan kurutma aşamalarında hesaplanan ağırlık ve NO değerleri verilmiştir. Kurutma işlemine geçmeden önce suya doymuş kayısı yaprağının ağırlığı $407 \mathrm{mg}$ olarak tartılmıştır. Kurutmanın her adımında kayısı yaprağının ağırlığı düşerek $115 \mathrm{mg}$ 'da sabit kalmıştır. $\mathrm{Bu}$ ağırlık, yaprağın firında $70^{\circ}$ 'de 12 saat bekletilerek elde edilmiş ve tamamen kurutulmuş olan ağırlıktır. Tablo 1'den anlaşılacağg gibi, bu ağırlık azalmasına bağlı olarak nem miktarı ve NO da düşmüştür. Suya doymuş kayısı yaprağı kurutulmadan önceki NO değeri \%100 iken, tamamen kurutulmuş yapraktaki nem oranı ise $\% 0$ olarak Denklem 3 ve Denklem 4'e göre hesaplanmıştır. Benzer şekilde, suya doymuş erik yaprağı ağırlığı 394 mg iken, tamamen kurutulmuş numunenin ağırlığı 148 mg'dır.

Suya doymuş yaprağın ağırlı̆̆ $m_{\text {doymus }}$ iken tamamen kurumuş yaprağın ağırllğg 1 ise $m_{\text {kuru }}$ 'dur. Yaprağın içerdiği su miktarı Denklem 3'e göre hesaplanabilir (van Emmerik, 2013).

Su miktarl $=m_{\text {doymuş }}-m_{\text {kuru }}$

Yaprakların nem oranı, Denklem 4'le elde edilebilir. Burada $m_{\text {ölçülen }}$ her bir kurutma adımında ölçülen yaprağın ağırlığıdır.

$N O=\frac{m_{\text {ölçülen }}-m_{\text {kuru }}}{\text { Su miktarl }}$

Tablo 1. Dielektrik ölçümleri yapılan kayısı ve erik yaprakların ağırlıkları ve NO değişimi

\begin{tabular}{cccc|cccc}
\hline \multicolumn{3}{c}{ Kayısı yaprağı } & \multicolumn{4}{c}{ Erik yaprağı } \\
\hline $\begin{array}{c}\text { Toplam } \\
\begin{array}{c}\text { ağırlık } \\
(\mathrm{mg})\end{array}\end{array}$ & $\begin{array}{c}\text { Kurumuş } \\
\text { ağırlık } \\
(\mathrm{mg})\end{array}$ & $\begin{array}{c}\text { Nem miktarı } \\
(\mathrm{mg})\end{array}$ & $\begin{array}{c}\text { Nem } \\
\text { oranı } \\
(\%)\end{array}$ & $\begin{array}{c}\text { Toplam } \\
\text { ağırlık } \\
(\mathrm{mg})\end{array}$ & $\begin{array}{c}\text { Kurumuş } \\
\text { ağırlık } \\
(\mathrm{mg})\end{array}$ & $\begin{array}{c}\text { Nem miktarı } \\
(\mathrm{mg})\end{array}$ & $\begin{array}{c}\text { Nem } \\
\text { oranı } \\
(\%)\end{array}$ \\
\hline 407 & 115 & 292 & 100 & 394 & 148 & 246 & 100 \\
198 & 115 & 83 & 28.42 & 250 & 148 & 102 & 41.46 \\
147 & 115 & 32 & 10.96 & 199 & 148 & 51 & 20.73 \\
130 & 115 & 15 & 5.14 & 176 & 148 & 28 & 11.38 \\
119 & 115 & 4 & 1.37 & 164 & 148 & 16 & 6.50 \\
115 & 115 & 0 & 0 & 148 & 148 & 0 & 0 \\
\hline
\end{tabular}

NO değerinin dielektrik sabiti üzerindeki etkisini görebilmek için ölçülmüş S-parametreleri değerlerini kullanarak bağıl dielektrik sabitinin hesaplanmıştır. Literatürde bu hesaplamayla ilgili çeşitli algoritmalar bulunmasına rağmen, en çok bilinen ve yaygın olarak kullanılan yöntem,
Nicolson-Ross-Weir (NRW) algoritmasıdır (Nicolson ve Ross, 1970; Weir, 1974). Bu çalışmada NRW modeli kullanılarak yaprakların dielektrik özellikleri hesaplanmıştır. Bu NRW algoritmasının akış diyagramı (Yaw, 2012), Şekil 2'de verilmiştir. 


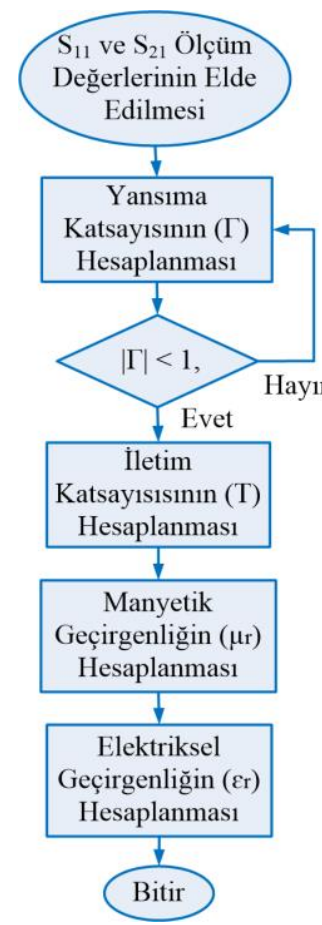

Şekil 2. NRW algoritmasının akış diyagramı

\subsection{Sistematik Hataların Ortadan Kaldırılması}

Dielektrik ölçümlerde sistematik hataları ortadan kaldırmak için yaygın olarak kullanılan yöntemler, gömülü ve Doğrudan Yansıma Hatt1 (DYH) yöntemleridir. Gömülü yönteminde, teste kullanılan modelin hatalarını ortadan kaldırmak için matematiksel ifadelerden yararlanılır. $\mathrm{Bu}$ yöntem, genellikle kalibrasyon yöntemlerinin kullanılmadığı koaksiyel olmayan Test Altındaki Cihazlarda (TAC) tercih edilir (Uygulama notlar1, 2004). TAC'1n ölçümlerindeki hataların giderilmesinde, $S_{11}$ ve $S_{22}$ parametrelerinden yararlanılır. Bundan dolayı bu işlem, modeldeki hataların TAC yapilmadan uygulanamaz. Dielektrik ölçümlerinde kullanılan plastik camlar,
TAC gibi davrandığ 1 için çalışma frekans bölgesinde S-parametrelerinin ölçülmesi gerekir. Dolayısıyla hem flanş hem de plastik camların etkileri numunenin olduğu ve olmadığ 1 durumlar için referans ölçümler yapılmalı ve dikkate alınmalıdır. Bunun için bu durumun literatürdeki yöntemlerle uyumlu olmasına dikkat edilmelidir (Helhel ve Kurnaz, 2016).

Dielektrik ölçümlerde oluşabilecek hataları en aza indirmek için farklı türde kalibrasyon yöntemleri vardır. Bunların arasında Doğrudan Yansıma Hattı Yöntemi, yaygın olarak kullanılan ve doğru sonuçlar veren bir yöntemdir (Ye vd., 2016). Bu teknik, ölçüm yöntemlerindeki doğruluğu gösterebilen bir referans yöntem olarak da bilinir. $\mathrm{Bu}$ yüzden, bu yöntemin doğruluğunu doğrudan etkileyebilecek hataların kaynakları dikkate alınmalıdır. Düşük frekanslarda ihmal edilen hata oranları, yüksek frekanslarda ölçüm doğruluğunu daha fazla etkiler.

\section{2. Ölçüm ve Kalibrasyon Yöntemini Doğrulama Testi}

Teflon, dielektrik ölçüm doğruluğunda yaygın olarak kullanilan ve bilinen bir malzemedir (Kumar vd., 2007). Bu malzemenin $\varepsilon^{\prime}$ ve $\varepsilon^{\prime \prime}$ değerleri frekansa göre değişim oluşmamakta olup, sırasıyla 2 ve 0 'dır. Bu çalışmada kalınlığ $2,5 \mathrm{~mm}$ olan teflon levha kullanilarak dielektrik parametrelerinin ölçümü yapılmıştır. Şekil 3 incelendiğinde teflon malzemenin ölçülen $\varepsilon^{\prime}$ ve $\varepsilon^{\prime \prime}$ değerleri, teorik değerlere yakın değerler elde edilmiștir. Böylece sistematik hataları ortadan kaldırmak amacıyla hazırlanan test düzeneği ve uygulanan kalibrasyon yönteminin doğruluğu tespit edilmiş olur.

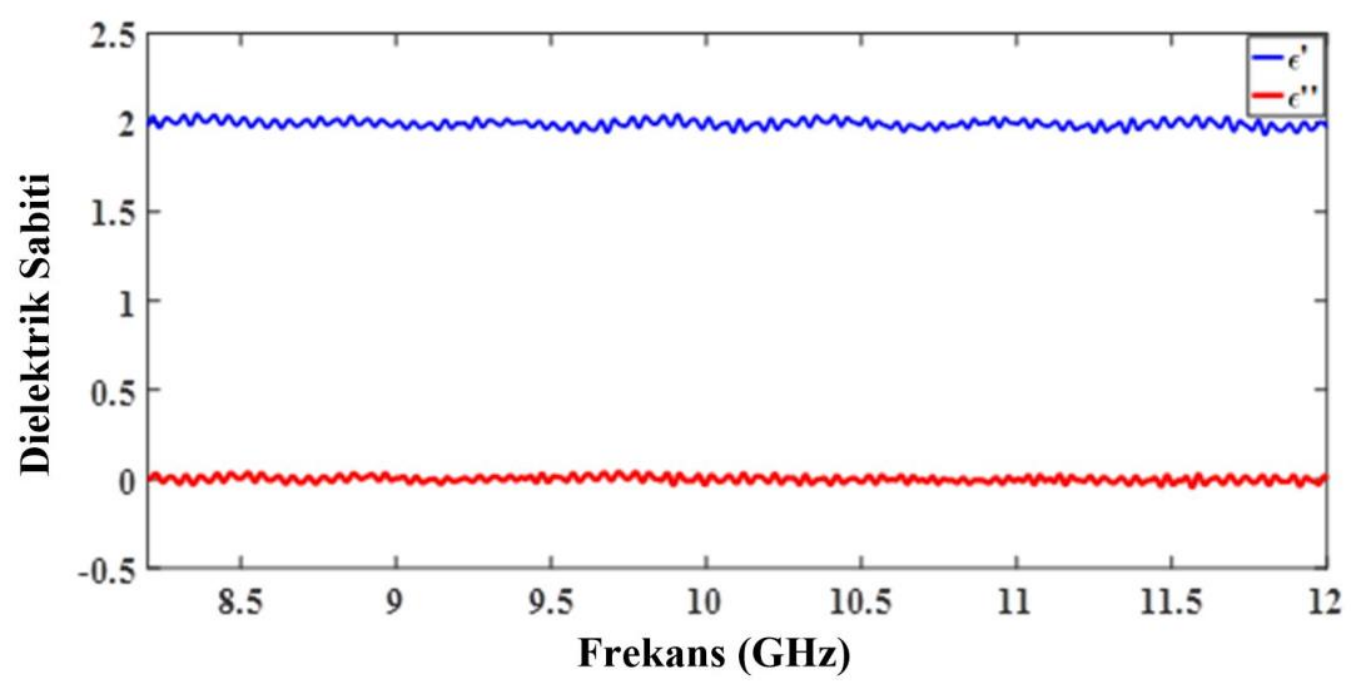

Şekil 3. 2,5 mm kalınlığındaki teflon malzeme için ölçülen dielektrik parametreleri 


\section{3. Ölçüm Sonuçları ve Önerilen Model}

Giriş bölümünde belirtildiği gibi ölçümlerde kayıs1 ve erik yaprakları numune olarak kullanılmıştır. Dalga kılavuzu olarak 3,30-4,90 $\mathrm{GHz}$ frekans bandına uyumlu WR229 dalga kılavuzu kullanılmıştır. Her bir numune için $\varepsilon^{\prime}$ ve $\varepsilon^{\prime \prime}$ değerleri $24^{\circ} \mathrm{C}$ oda sicaklığında, frekans ve NO değerlerine bağlı olarak ölçülmüştür. VNA'dan elde edilen $S_{11}$ ve $S_{21}$ değerleri kullanılarak 2 .
Bölüm'de bahsedilen NRW algoritmas1 kullanılarak $\varepsilon^{\prime}$ ve $\varepsilon^{\prime \prime}$ değerleri hesaplanmıştır. Bu frekans bandı için ölçüm adım sayısı $2 \mathrm{MHz}$ olup 801 farklı frekans noktasında ölçüm yapılmıştır.

Şekil 4'te kayısı yaprakları için ölçülen $\varepsilon^{\prime}$ değerleri verilmiştir. $\varepsilon$ ' değerinin, frekans azalışı ve NO artışı ile arttığı gözlenmiştir. Bu benzer değişimlerin $\varepsilon^{\prime \prime}$ değerleri için de geçerli olduğu Şekil 5'te görülmektedir.

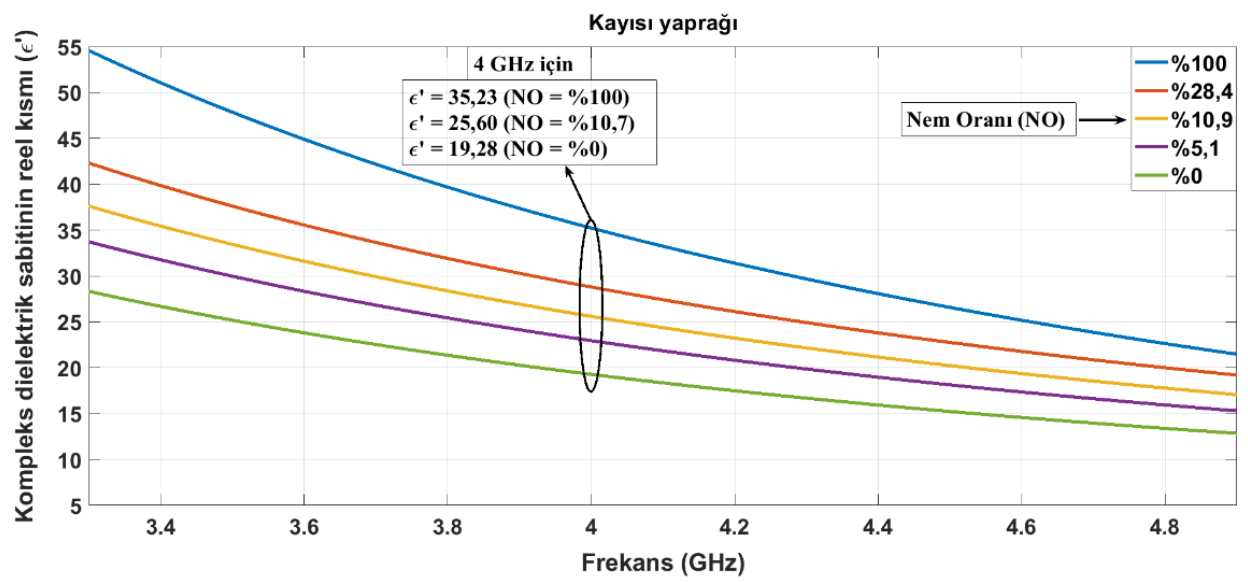

Şekil 4. Kayısı yaprakları için $\varepsilon^{\prime}$ değerinin frekans ve NO değerlerine göre değişimi

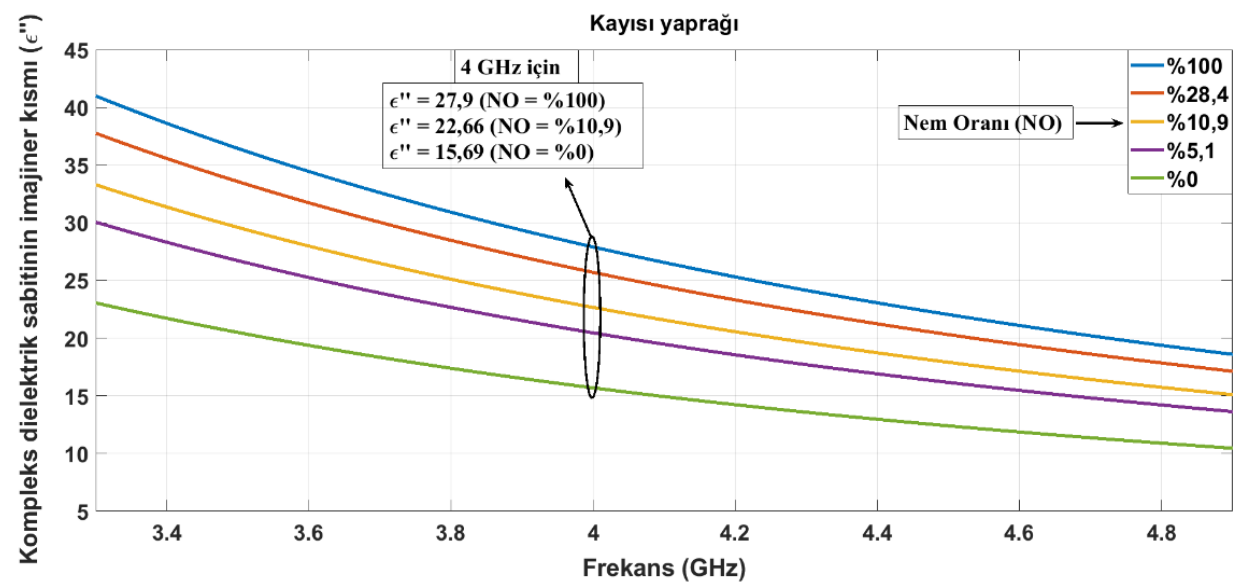

Şekil 5. Kayısı yaprakları için $\varepsilon^{\prime \prime}$ değerinin frekans ve NO değerlerine göre değişimi

Şekil 6 ve Şekil 7'de erik yaprakları için elde edilen $\varepsilon^{\prime}$ ve $\varepsilon^{\prime \prime}$ değerleri verilmiștir. Frekansa bağl1 olarak $\varepsilon^{\prime}$ ve $\varepsilon^{\prime \prime}$ değerleri, eksponansiyel olarak azalmaktadır. NO'ya bağlı olarak ise bu değerler dikey eksende azaldığ 1 görülmüştür. Literatürde, saf suyun $\varepsilon^{\prime}$ değerleri, 3,30-4,90 GHz bandı için 78-74 aralığında değişmektedir (Ulaby ve ElRayes, 1987). Bu çalışmada elde edilen sonuçlar için suya doymuş yaprağın $\varepsilon^{\prime}$ ve $\varepsilon^{\prime \prime}$ değerleri, kuru yaprağınkine göre daha yüksektir ve bu durum NO'dan dolayı beklenen durumdur.

Kayısı yapraklarının ölçüm sonuçlarından elde edilen veriler kullanarak eğri uydurma yöntemiyle yeni bir model elde edilmiştir. Bu modelle, sabit sicaklıkta $\left(24^{\circ} \mathrm{C}\right)$ frekans ve NO'ya bağl1 dielektrik sabitini hesaplamak hedeflenmiştir. Denklem 5'te verilen bu model, iki değişkenli ikinci dereceden bir kuvvet fonksiyonundan oluşur.

$$
\begin{aligned}
& \varepsilon_{r}(f, m)=a+b \cdot f^{-c}+d \cdot m^{e}+g \cdot f^{-c} \cdot m^{e} \\
& \varepsilon_{\mathrm{r}}(\mathrm{f}, \mathrm{m})=\mathrm{a}+\mathrm{b} \cdot \mathrm{f}^{-\mathrm{c}}+\mathrm{d} \cdot \mathrm{m}^{\mathrm{e}}+\mathrm{g} \cdot \mathrm{f}^{-\mathrm{c} *} \mathrm{~m}^{\mathrm{e}} \\
& \varepsilon_{r}=\sqrt{\left(\varepsilon^{\prime}\right)^{2}+\left(\varepsilon^{\prime \prime}\right)^{2}} \varepsilon_{\mathrm{r}}=\sqrt{\varepsilon^{\prime 2}+\varepsilon^{\prime 2}}
\end{aligned}
$$

Burada, $\varepsilon_{r}$ dielektrik sabiti, f $\mathrm{GHz}$ cinsinden frekans, $\mathrm{m}$, 0-100 arasında değişen NO'dur. 
Denklem 6'da verilen $\varepsilon_{r}$ değeri, malzemenin dielektrik sabitinin hem reel hem de sanal kısmını içerdiği için modelde tercih edilmiştir. Kayısı yaprağı için WR229 dalga k1lavuzu için elde edilmiş modelin katsayıları $a=1,263, b=378,4$, $c=2,005, \quad d=-0,808, \quad e=0,3679, \quad g=73,92$ şeklindedir. $\mathrm{Bu}$ modeli oluşturmak için, Tablo 1'de kayısı yaprağının kurutma adımlarında hesaplanan 6 farklı NO değeri, veri olarak kullanılmıştır. Elde edilen modelin doğruluğunu test etmek için daha önce ölçümlerde kullanılan kayısı yapraklarından farklı ve \%29 NO'ya sahip başka bir kayısı yaprağı test numunesi olarak seçilmiştir. Önerilen modelde de aynı NO değerine sahip olması için Denklem 5'te verilen m değeri 29 olarak girilmiştir. Şekil 8'de önerilen modelle test için seçilen kayısı yaprağının ölçülen değerleri karşılaştırılmıştır. Sonuçların birbiriyle çok uyumlu olduğu görülmektedir. Modelin performansını görmek için determinasyon katsayısı $\mathrm{R}^{2}$ ve Hataların Ortalama Kare Kökü (RMSE) değerleri, tüm frekans ve NO değerlerine temel alınarak MATLAB $^{\circledR}$ programiyla hesaplanmıştır. Buna göre modelin $\mathrm{R}^{2}$ ve RMSE değerleri, sirasıly 0,996 ve 0,653 olarak elde edilmiştir.

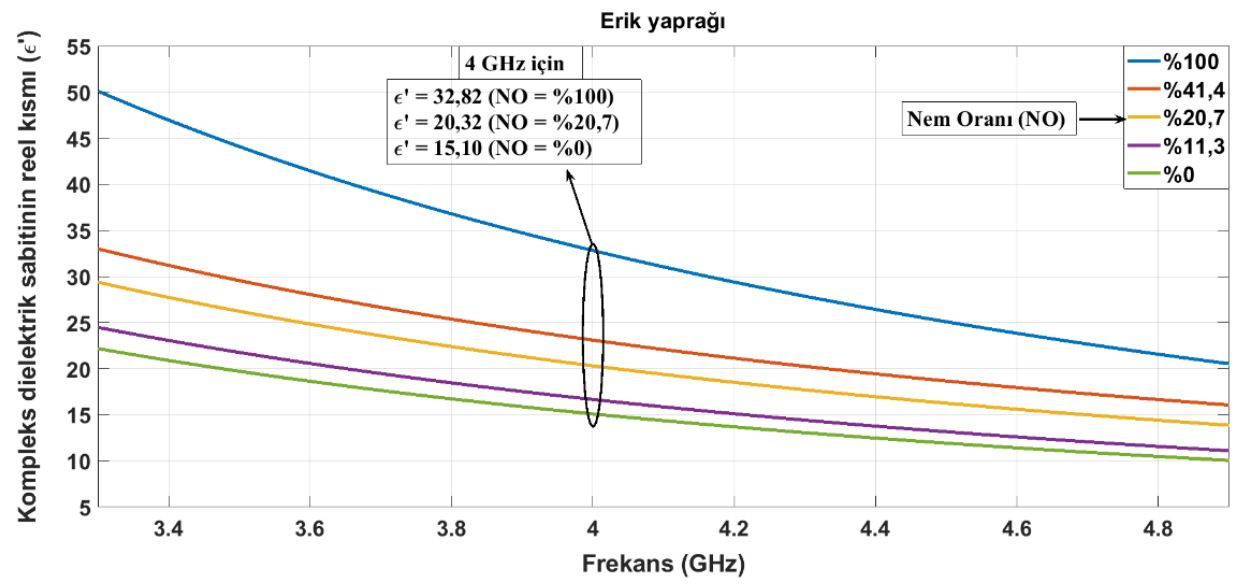

Şekil 6. Erik yaprakları için $\varepsilon^{\prime}$ değerinin frekans ve NO değerlerine göre değişimi

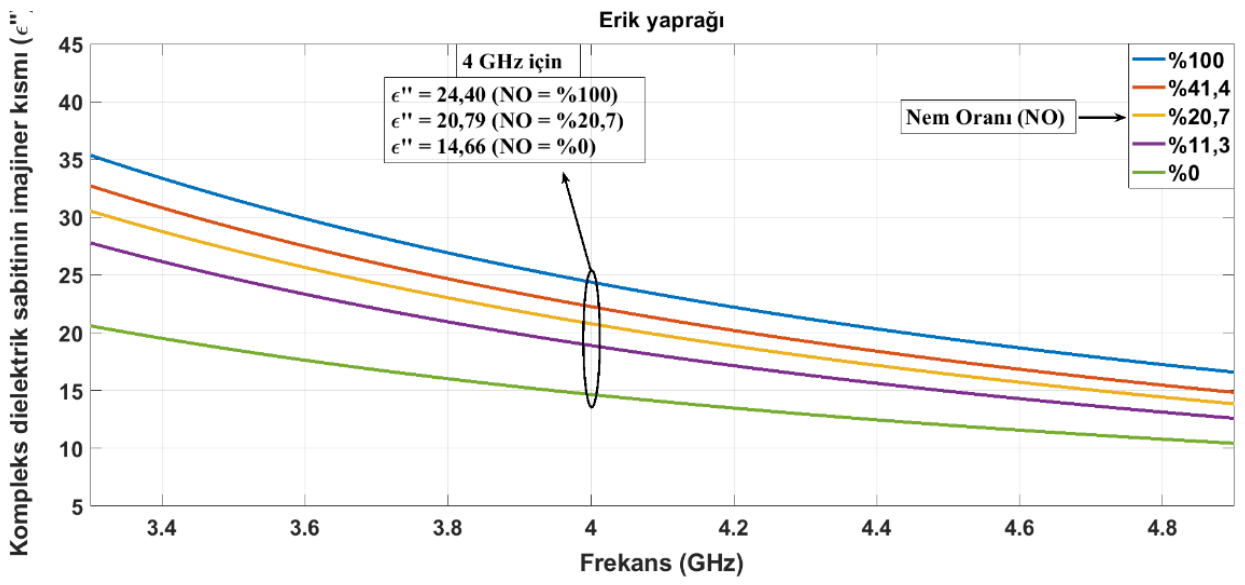

Şekil 7. Erik yaprakları için $\varepsilon^{\prime \prime}$ değerinin frekans ve NO değerlerine göre değişimi

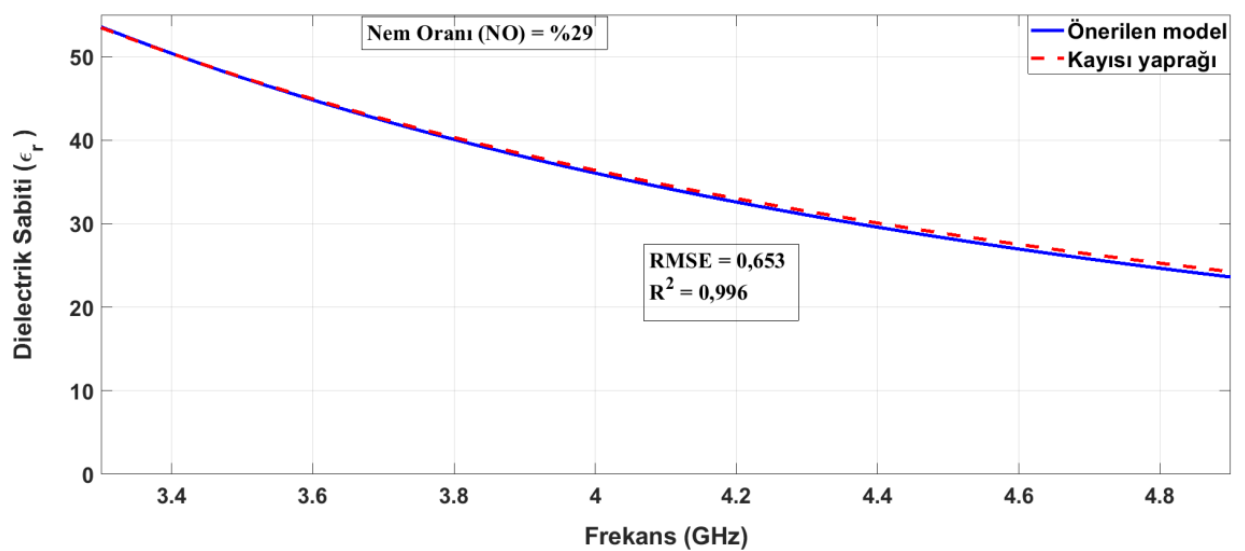

Şekil 8. Kayısı yaprağı ölçüm sonuçlarıyla önerilen modelin doğruluğunun test edilmesi 
Kayısı yaprağına ait ölçüm verilerini kullanarak oluşturulan modelin erik yaprağ 1 için kullanılabilirliği test edilmiştir. MC değeri \%23 olan bir erik yaprağı ile aynı nem oranına sahip $(m=0,23)$ önerilen modelin sonuçları karşılaştırılmıştır. Sonuçların birbiri ile çok uyumlu olduğu Şekil 9'da görülmüştür. Bu karşılaştırma, aynı akraba ailesi içinde olan bir bitkinin yapraklarından elde edilen bir modelin aynı ailedeki diğer bitki türleri için uyumlu olabileceği hususunda fikir vermektedir.

Kayısı yaprağına ait ölçüm verilerini kullanarak oluşturulan modelin erik yaprağı için kullanılabilirliği test edilmiştir. Burada, NO değeri $\% 23$ olan bir erik yaprağıyla aynı NO değerine sahip $(\mathrm{m}=23)$ önerilen modelin sonuçları karşılaştırılmıştır. Bu sonuçların birbiriyle çok uyumlu olduğu Şekil 9'da görülmüştür. Bu karşılaştırma, aynı cins ve aynı aile içinde olan bir bitkinin yapraklarından elde edilen bir modelin aynı cinsteki diğer bitki türleri için uyumlu olabileceği hususunda fikir vermektedir. Kayısı ve erik, aynı familya (Rosacea), takım (Rosales) ve cins (Prunus) grubunda bulunur. Bundan dolay1 kayısı yaprağı ölçüm verileriyle elde edilen model, erik yaprağı ölçüm sonuçlarıyla karşılaştırılmıştır.

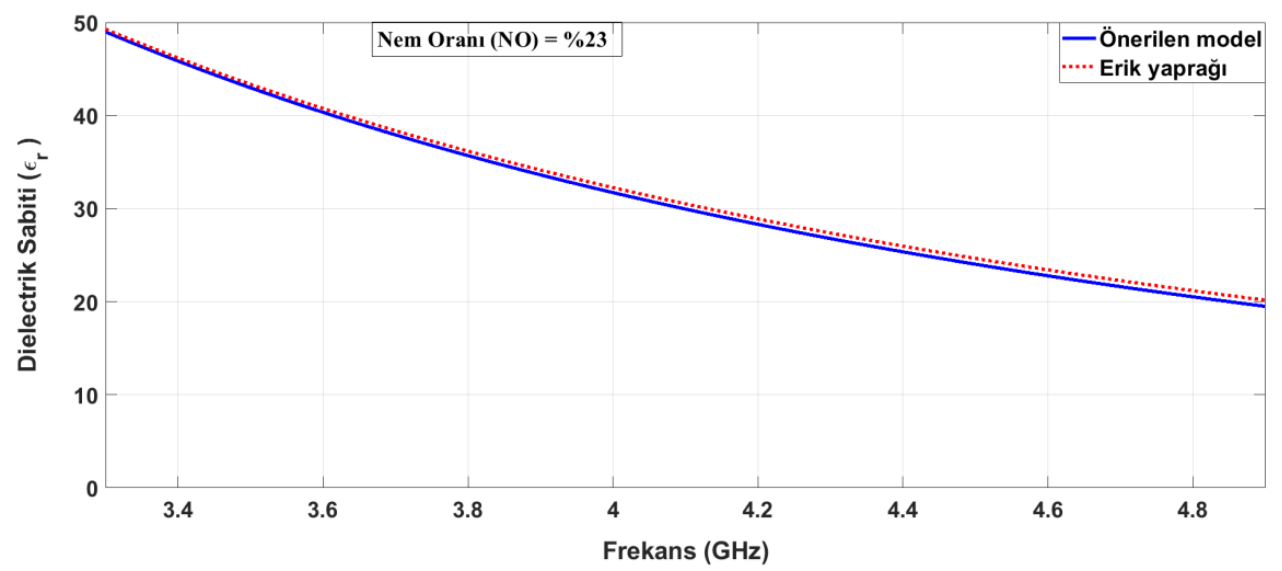

Şekil 9. Kayısı yaprağı modelinin erik yaprağı ölçüm sonuçlarıyla karşılaştırılması

Tablo 2'de bu çalışmada elde edilen sonuçlarla, yakın özellikteki diğer bitki yapraklarına ait ölçümlerin karşılaştırılması verilmiştir. $\mathrm{Bu}$ karşılaştırma tablosuna bakılınca ölçüm yapılan ve yeni model geliştirmek amaciyla kullanılan kayısı yaprağının dielektrik parametrelerinin literatürdeki diğer yaprakların dielektrik parametrelerine benzer olduğu görülmektedir. Bunun ise, yapraklardaki nem oranı ve frekansın dielektrik parametrelerdeki belirleyiciliğinden kaynaklandığı düşünülmektedir.

Tablo 2. Literatür karşılaştırması

\begin{tabular}{c|ccccc}
\hline & $\boldsymbol{\varepsilon}^{\prime}$ & $\boldsymbol{\varepsilon}^{\prime \prime}$ & Frekans (GHz) & Nem & Ref \\
\hline Armut Yaprağı & $19-12$ & $5-3,2$ & $3,3-4,9$ & $\% 63$ & (Li vd., 2014) \\
Misır Yaprağı & $20-18$ & $5,5-4$ & $3,3-4,9$ & $\% 63$ & (Li vd., 2014) \\
Misır Yaprağı & $34-28$ & $8-5$ & $3,3-4,9$ & $\% 60$ & (Ulaby ve El-Rayes, \\
Yonca Yaprağ & $38-33$ & $19-13$ & $3,3-4,9$ & $\% 73$ & (Shrestha vd., 2011) \\
Kaucuk Yaprağ & $22-18$ & $8-6$ & $3,3-4,9$ & $\% 46$ & (Chuah vd., 1997) \\
Bu çalışma (Kayısı & $32-19$ & $34-23$ & $3,3-4,9$ & $\% 41$ & \\
Yaprağı) & & & & \\
\hline
\end{tabular}

\section{Sonuçlar ve Öneriler}

Bitki örtüsüne ait dielektrik parametreler, çok değişik amaçlarla kullanılmakta olup, gelişen teknolojik uygulamaların tarımsal ürünlerde yaygınlaşabilmesi için bilinmesi gereken temel parametrelerdir. UA, izleme/kontrol uygulamaları, 1sıtma ve kurutma işlemleri gibi mikrodalga teknikleri, bitkisel ürünlerin üretim kalite ve verimindeki artışları amaçlar. Bunun için, bitkisel malzemelerin dielektrik özelliklerinin doğru olarak belirlenmesi gerekir. Elde edilen sonuçların ülkemizin hemen hemen her bölgesinde yaygın bir şekilde üretimi yapılan kayısı ve erik üretiminde geleneksel yöntemler yerine teknolojik uygulamaların kullanımında yardımcı olacağı düşünülmektedir. 
$\mathrm{Bu}$ deneysel çalışmada, kayısı ve erik yapraklarının dielektrik parametreleri Doğrudan Yansıma Hattı Yöntemi kullanılarak ölçülmüştür. Yapılan ölçümler WR229 dalga kılavuzuyla 3,30$4,90 \mathrm{GHz}$ frekans bandında gerçekleştirilmiştir. Bütün frekans bandında kayısı için $\varepsilon^{\prime}$ değerleri 12$55, \varepsilon^{\prime \prime}$ değerleri ise 10-41 aralığında değiştiği tespit edilmiştir. Sonuçlar ölçüm yapılan yapraklarda dielektrik parametrelerin NO ve frekansa bağlı olduğunu ortaya koymaktadır. NO değerine bağlı olan dielektrik parametreler, bitkilerin su ihtiyacinın tespit edilerek eksik veya fazla sulamadan doğacak zararların önüne geçilmesinde önemli etkendir. Dolayısıyla, bu çalışmadaki elde edilen sonuçlar ve değerlendirmeler, mikrodalga tekniklerinin bitki örtüsünün uzaktan takip edilerek izleme ve yönetilmesinde ve verimli bir şekilde uygulanmasında yol gösterici olabilir.

\section{Teşekkür}

$\mathrm{Bu}$ çalışmadaki ölçümlerin gerçekleştirildiği Akdeniz Üniversitesi Endüstriyel ve Medikal Uygulamalar Mikrodalga Araştırma Merkezi (EMUMAM)'a teşekkür ederim.

\section{Kaynaklar}

Afzal, A. ve Mousavi, S.F., 2008. Estimation of moisture in maize leaf by measuring leaf dielectric constant. International Journal of Agriculture and Biology, 10, 66-68.

Baharudin, E., Ismail, A., Alhawari, A.R.H. Zainudin, E.S., Majid, D.L. ve Seman, F.C., 2015. Investigation on the dielectric properties of pulverized oil palm frond and pineapple leaf fiber for X-band microwave absorber application. Advanced Materials Research, 488491.

Ballester-Berman, J.D., López-Sánchez, J.M. ve Fortuny-Guasch, J., 2005. Retrieval of biophysical parameters of agricultural crops using polarimetric SAR interferometry. IEEE Transactions on Geoscience and Remote Sensing, 43 (4), 683-694

Chuah, H., Kam, S. ve Chye, Y., 1997. Microwave dielectric properties of rubber and oil palm leaf samples: measurement and modelling. International Journal of Remote Sensing, 18, 2623-2639.

Colak, B., 2019. Moisture content effect of banana leaves to radio frequency absorbing. Microwave and Optical Technology Letters, 61, 2591-2595.
Faktorová, D. ve Isteníková, K., 2011. Modelling of scattering parameters in biological tissues. Skin, $1,1-7$.

Helhel, S. ve Kurnaz, O., 2016. Buried metal detection within the wooden block by X-band measurements. Microwave and optical technology letters, 58, 1245-1253.

Jayamani, E., Hamdan, S., Ezhumalai, P. ve Bakri, M.K., 2016. Investigation on dielectric and sound absorption properties of banana fibers reinforced epoxy composites. Jurnal Teknologi, 78, 97-103.

Kamaruddin, M.J., Yusof, M. Ngadi, N., Zakaria, Z., Arsad, A. ve Kidam, K., 2017. Dielectric Properties for Extraction of Orthosiphon Stamineus (Java Tea) Leaves. Chemical Engineering Transactions, 56, 1771-1776.

Kaur, R., Aul, G. D. ve Chawla, V., 2015. Improved reflection loss performance of dried banana leaves pyramidal microwave absorbers by coal for application in anechoic chambers. Progress In Electromagnetics Research, 43, 157-164.

Khaled, D., Novas, N., Gazquez, J., Garcia, R. ve Manzano-Agugliaro, F., 2015. Fruit and vegetable quality assessment via dielectric sensing. Sensors, 15, 15363-15397.

Kocakusak, A., Colak, B. ve Helhel, S., 2016. Frequency dependent complex dielectric permittivity of rubber and magnolia leaves and leaf water content relation. Journal of Microwave Power and Electromagnetic Energy, 50, 294-307.

Kraszewski, A.W. ve Nelson, S.O., 2004. Microwave permittivity determination in agricultural products. Journal of Microwave Power and Electromagnetic Energy, 39, 41-52.

Krraoui, H., Mejri, F. ve Aguili, T., 2016. Dielectric constant measurement of materials by a microwave technique: application to the characterization of vegetation leaves. Journal of Electromagnetic Waves and Applications, 30, $1643-1660$

Kumar, A., Sharma, S. ve Singh, G., 2007. Measurement of dielectric constant and loss factor of the dielectric material at microwave frequencies. Progress In Electromagnetics Research, 69, 47-54.

Li, Z., Zeng, J., Chen, Q. ve Bi, H., 2014. The measurement and model construction of complex permittivity of vegetation. Science China Earth Sciences, 57 (4), 729-740.

Navarrete, A., Mato, R., Dimitrakis, G., Lester, E., Robinson, J. ve Cocero, M., 2011. Measurement 
and estimation of aromatic plant dielectric properties. Application to low moisture rosemary. Industrial Crops and Products, 33, 697-703.

Nelson, S.O., 1991. Dielectric properties of agricultural products-measurements and applications. IEEE Transactions on Electrical Insulation,26, 845869.

Nelson, S.O., 2006. Agricultural applications of dielectric measurements. IEEE Transactions on Dielectrics and Electrical Insulation, 13, 688702.

Nelson, S.O., 1991. Dielectric properties measurement techniques and applications. Transactions of the ASAE-American Society of Agricultural Engineers, 42, 523-530.

Nicolson, A. ve Ross, G., 1970. Measurement of the intrinsic properties of materials by time-domain techniques. IEEE Transactions on instrumentation and measurement, 19, 377-382.

Romanov, A.N. ve Ulanov, P.N., 2018. Seasonal Differences in Dielectric Properties of Dwarf Woody Tundra Vegetation in a Microwave Range. IEEE Transactions on Geoscience and Remote Sensing, 57, 3119-3125.

Shrestha, B.L., Wood, H.C. ve Sokhansanj, S., 2011. Microwave dielectric properties of alfalfa leaves from 0.3 to $18 \mathrm{GHz}$. IEEE Transactions on Instrumentation and Measurement, 60, 29262933.

Trabelsi, S., Mckeown, M. S. ve Nelson, S.O., 2016. Dielectric properties-based method for rapid and nondestructive moisture sensing in almonds. Journal of Microwave Power and Electromagnetic Energy, 50, 94-105.

Ulaby, F.T. ve El-Rayes, M.A., 1987. Microwave dielectric spectrum of vegetation-Part II: Dual- dispersion model. IEEE Transactions on Geoscience and Remote Sensing, 550-557.

Ulaby, F.T. ve Jedlicka, R., 1984. Microwave dielectric properties of plant materials. IEEE Transactions on Geoscience and Remote Sensing, 406-415.

Uygulama Notları, 2004. De-embedding and Embedding S-Parameter Networks Using a Vector Network Analyzer.

Van Emmerik, T. H., 2013. Diurnal differences in vegetation dielectric constant as a measure of water stress. Yüksek Lisans Tezi, Delft Üniversitesi, Hollanda.

Van Emmerik, T., Steele-Dunne, S., Judge, J. ve van de Giesen, N., 2015. A comparison between leaf dielectric properties of stressed and unstressed tomato plants, IEEE International Geoscience and Remote Sensing Symposium (IGARSS), 275-278.

Venkatesh, M. ve Raghavan, G., 2005. An overview of dielectric properties measuring techniques. Canadian Biosystems Engineering, 47, 15-30.

Weir, W.B., 1974. Automatic measurement of complex dielectric constant and permeability at microwave frequencies. Proceedings of the IEEE, 62, 33-36.

Yaw, K.C., 2012. Measurement of Dielectric Material Properties. Application Note, Rhode \& Schwarz. https://cdn.rohde-schwarz.com/pws /dl_downloads/dl_application/00aps_undefined/ RAC-0607-0019_1_5E.pdf.

Ye, L., Li, C., Sun, X., Jin, S. Chen, B. ve Ye, X., 2016. Thru-Reflect-Line Calibration technique: error analysis for characteristic impedance variations in the line standards. IEEE Transactions on Electromagnetic Compatibility, 59, 779-788. 